\title{
A novel osteoporosis model with ascorbic acid deficiency in Akr1A1 gene knockout mice
}

\author{
Cheng-Wei Lai ${ }^{1,2, *}$, Hsiao-Ling Chen ${ }^{3, *}$, Min-Yu Tu1,4,5, Wei-Yu Lin ${ }^{1,2}$, Theresa \\ Röhrig $^{1,2}$, Shang-Hsun Yang ${ }^{6}$, Ying-Wei Lan ${ }^{1,7}$, Kowit-Yu Chong ${ }^{7,8}$ and Chuan-Mu \\ Chen ${ }^{1,2,9}$ \\ ${ }^{1}$ Department of Life Sciences, National Chung Hsing University, Taichung, Taiwan \\ ${ }^{2}$ Agricultural Biotechnology Center, National Chung Hsing University, Taichung, Taiwan \\ 3 Department of Bioresources, Da-Yeh University, Changhua, Taiwan \\ ${ }^{4}$ Department of Orthopaedic Surgery, Taichung Armed Forces General Hospital, Taichung, Taiwan and National Defense \\ Medical Center, Taipei, Taiwan \\ ${ }^{5}$ Department of Biomedical Engineering, Hungkuang University, Taichung, Taiwan \\ ${ }^{6}$ Department of Physiology and Institute of Basic Medical Sciences, National Cheng Kung University, Tainan, Taiwan \\ 7 Department of Medical Biotechnology and Laboratory Science, College of Medicine, Chang Gung University, Tao-Yuan, \\ Taiwan \\ ${ }^{8}$ Department of Thoracic Medicine, Chang Gung Memorial Hospital at Linkou, Tao-Yuan, Taiwan \\ ${ }^{9}$ Rong-Hsing Translational Medicine Center, and iEGG Center, National Chung Hsing University, Taichung, Taiwan \\ ${ }^{*}$ These authors have contributed equally to this study \\ Correspondence to: Chuan-Mu Chen, email: chchen1@dragon.nchu.edu.tw \\ Kowit-Yu Chong, email: kchong@mail.cgu.edu.tw
}

Keywords: osteoporosis; AkrlAl gene; ascorbic acid; knockout mice; micro-CT imaging; trabecular bone; cortical bone; Pathology Section

Received: August 13, $2016 \quad$ Accepted: December 07, 2016 Published: January 02, 2017

\section{ABSTRACT}

The AKR1A1 protein is a member of the aldo-keto reductase superfamily that is responsible for the conversion of D-glucuronate to L-gulonate in the ascorbic acid (vitamin C) synthesis pathway. In a pCAG-eGFP transgenic mouse line that was produced by pronuclear microinjection, the integration of the transgene resulted in a 30-kb genomic DNA deletion, including the Akr1A1 gene, and thus caused the knockout (KO) of the Akr1A1 gene and targeting of the eGFP gene. The Akr1A1 KO mice (Akr1A1 ${ }^{\text {GFP/eGFP }}$ ) exhibited insufficient serum ascorbic acid levels, abnormal bone development and osteoporosis. Using micro-CT analysis, the results showed that the microarchitecture of the 12-week-old Akr1A1 ${ }^{\text {GFP/eGFP }}$ mouse femur was shorter in length and exhibited less cortical bone thickness, enlargement of the bone marrow cavity and a complete loss of the trabecular bone in the distal femur. The femoral head and neck of the proximal femur also showed a severe loss of bone mass. Based on the decreased levels of serum osteocalcin and osteoblast activity in the Akr1A1 ${ }^{\text {GFP/ }}$ eGFP mice, the osteoporosis might be caused by impaired bone formation. In addition, administration of ascorbic acid to the Akr1A1 ${ }^{\text {eGFP/eGFP }}$ mice significantly prevented the condition of osteoporotic femurs and increased bone formation. Therefore, through ascorbic acid administration, the Akr1A1 KO mice exhibited controllable osteoporosis and may serve as a novel model for osteoporotic research.

\section{INTRODUCTION}

According to the National Institutes of Health (NIH) consensus statement in 2000 , osteoporosis is defined as a skeletal disorder characterized by compromised bone strength, predisposing individuals to an increased risk of fracture [1]. The disease has become one of the major threats to public health due to the increased risk of bone fracture, including fracture of the hip and vertebrae, which severely increases disability and mortality [2]. However, 
the prevalence of osteoporosis is steadily increasing because of the demographic change in aging societies. In the United States, more than 10 million people are estimated to have osteoporosis, and more than $30 \%$ of the population that is over 50 years old in Taiwan is diagnosed with osteoporosis [3].

Bone mineral density (BMD), which is measured by dual-energy X-ray absorptiometry (DXA), is the predominant measurement that is used for the diagnosis of osteoporosis [4]. The World Health Organization (WHO) defines a diagnosis of osteoporosis as a peak bone mass (T-score) BMD of 2.5 standard deviations below the mean (T-score $<-2.5$ ), and a T-score between -1 to -2.5 is considered osteopenia [5]. Based on the causes, osteoporosis can be divided into primary and secondary osteoporosis [6,7]. Primary osteoporosis occurs mainly because of natural ageing. The BMD of men and women begins to decline after midlife, especially in postmenopausal women, who experience rapid bone loss in the early years of postmenopause. Two-thirds of osteoporotic fractures are observed in postmenopausal women [8], and, similarly, hypogonadism also increases bone loss in elderly men. In addition, secondary osteoporosis is usually caused by external factors, e.g., medications, endocrine, metabolism disorders and other conditions. However, osteoporosis can occur in all populations at all ages because of not only bone loss but also insufficient bone formation. Individuals who are deficient in nutrients (e.g., calcium, vitamin D and vitamin C), hormones (e.g., sex and growth hormones), and exercise, particularly during the critical bone formation period, may have a reduced peak bone mass throughout young adulthood and are consequently at an increased risk of osteoporosis [1].

Bone metabolism is a continuous process. The dynamics of bone formation and resorption, which are carried out by osteoblasts and osteoclasts, respectively, comprise the bone remodeling cycle [9, 10]. During bone formation, bone morphogenetic proteins (BMPs) activate osteoblasts via the transcription factors Dlx5, Runx2 and Osx. The activated osteoblasts then synthesize an abundance of collagen type $\mathrm{I}$ as the framework of bone structure and mineralize the bone via alkaline phosphatase (ALP), osteopontin, osteocalcin and 1,25-dihydroxyvitamin D3 [11, 12]. Clinical and nutritional studies showed that insufficient intake of ascorbic acid can reduce bone density and increase the risk of fractures in humans $[13,14]$. The ascorbic acid synthesis pathway in many species, including mice and rats, involves 3 anabolic enzymes: glucuronate reductase (AKR1A1), which converts D-glucuronate to L-gulonate; gulonolactonase (SMP30), which converts L-gulonate to L-gulono- $\gamma$-lactone; and L-gulono- $\gamma$-lactone oxidase (GULO), which catalyzes the final step to produce L-ascorbic acid. However, unlike mice and rats, humans and other primates do not synthesize ascorbic acid due to a mutated and nonfunctional Gulo gene; therefore, the required ascorbic acid is only obtained from food.

In this study, we generated genetically modified mice that are unable to synthesize ascorbic acid due to a knockout (KO) of the ascorbic acid synthesis gene $A k r 1 A 1$. The mice displayed a rapid induction of osteoporosis after ascorbic acid withdrawal, which could be rescued by the addition of ascorbic acid into the dietary water. Through ascorbic acid administration and microcomputed tomography (micro-CT) analysis, the Akr $1 A 1$ knockout mice represent a controllable osteoporosis model that may allow for the mimicry of the desired features of human osteoporosis

\section{RESULTS}

\section{The characterization of $A \mathrm{kr} 1 \mathrm{Al} \mathrm{KO}$ mice}

The $p C A G-e G F P$ transgenic mouse line was generated by pronuclear microinjection. Using chromosome FISH and CELI-PCR [15], the results demonstrated that the integration of the transgene gave rise to a $30-\mathrm{kb}$ genomic DNA deletion that included exons 1-5 and introns 1-4 of the $A k r 1 A 1$ gene as well as the non-coding nucleotides between the $A k r l A 1$ and $P r d x l$ genes, resulting in the generation of $A k r l A 1 \mathrm{KO}$ mice (Figure 1A). Previous studies showed that AKR1A1 is an NADPH-dependent aldehyde reductase that is expressed in the liver [16, 17]. In the $A k r l A 1^{\text {eGFP/eGFP }} \mathrm{KO}$ mice, AkrlAl mRNA and protein expression was abolished in the livers, and mRNA expression was reduced by $50 \%$ in $A k r 1 A 1^{e G F P /+}$ mice compared with wild-type (WT) mice (Figure $1 \mathrm{~B}$ and $1 \mathrm{C}$ ).

The body weight of $A k r l A 1^{\text {eGFP/eGFP }} \mathrm{KO}$ mice displayed a significant decrease when compared with WT mice $(P<0.01)$, but $A k r 1 A 1^{e G F P / e G F P}+$ Vit. C treated group was able to restore the body weight to normal level (Supplementary Figure S1A). Furthermore, the results of liver pathological examination showed that $A k r 1 A 1$ gene knockout caused moderate severe aging of hepatocytes with intra nuclear inclusion body and glycogen accumulation in AkrlA1 eGFP/eGFP $^{\mathrm{KO}}$ mice (Supplementary Figure S1C) compared with WT mice (Supplementary Figure S1B) and $A k r 1 A 1^{e G F P / e G F P}+$ Vit. C treated group (Supplementary Figure S1D).

\section{The Akr1A1 KO mice exhibited ascorbic acid deficiency, increased ROS and osteoporosis which could be prevented by ascorbic acid supplementation}

The analysis of serum revealed that the concentration of ascorbic acid in AkrlA1 eGFP/eGFP mice 
$(1.25 \pm 0.23 \mu \mathrm{M})$ was significantly lower than that in $A k r l A 1^{G G F P /+}(51.35 \pm 8.14 \mu \mathrm{M})$ and WT $(55.05 \pm 7.73 \mu \mathrm{M})$ mice $(P<0.01)$, indicating that ascorbic acid synthesis was nearly abolished and resulting in insufficient ascorbic acid levels in the $A k r l A 1 \mathrm{KO}$ mice. However, there was no significant difference between the $A k r l A 1^{e G F P /+}$ and WT mice (Figure 2A). Additionally, after supplementation with freshly prepared ascorbic acid-containing water (350 $\mathrm{mg} / \mathrm{L})$, the serum ascorbic acid concentration increased in the AkrlA1 ${ }^{\text {eGFP/eGFP }}$ mice $\left(15.38 \pm 6.40 \mu \mathrm{M} ; P<10^{-4}\right.$ vs. AkrlA1 eGFP/eGFP mice) (Figure 2A). The ascorbic acid level in the mouse serum began to increase after 1 hour of supplementation and reached a steady level after 6 hours, and the ascorbic acid levels of the serum were between $10 \sim 15 \mu \mathrm{M}$ for at least 3 days (Figure $2 \mathrm{~B}$ and 2C). Although the female $A k r 1 A 1 \mathrm{KO}$ mice were able to become pregnant and deliver their young, they could not successfully rear their neonates throughout the lactation period. When ascorbic acid was supplied to the $A k r l A 1 \mathrm{KO}$ mice in the drinking water, these female and male $A k r 1 A 1 \mathrm{KO}$ mice were able to breed directly with no differences in growth compared to WT mice. These results indicated that the ascorbic acid deficiency severely inhibited the bone development of the $A k r 1 A 1 \mathrm{KO}$ mice. In previous studies, low ascorbic acid intake will increase ROS production [18]. In the present study, the ROS level in the $A k r 1 A 1 \mathrm{KO}$ mouse serum was significantly increased compared with WT mice $(P<0.05)$ and returned to normal after supplementation with ascorbic acid (Figure 2D). These results suggested that the supplied ascorbic acid was sufficient to reduce the ROS level, even though the ascorbic acid level was only one quarter of that in the Akr1A1 ${ }^{e G F P /+}$ and WT mice.

The risk of femoral fracture has been commonly used to evaluate osteoporosis, including the FDA guideline for evaluating the treatment of postmenopausal osteoporosis [19]. While rearing the $A k r 1 A 1 \mathrm{KO}$ mice, an abnormal walking posture was observed before the age of 6 months, and some of the mice became paralyzed at around 1 year of age. In the 12-week-old $A k r 1 A 1 \mathrm{KO}$ mice, the femurs shown abnormal structure where the distal femurs were enlarged and shortened. The coronal sections of the distal femurs in the AkrlA1 eGFP/eGFP $^{\text {mice }}$ showed that the trabecular bones were severely reduced compared with the AkrlA1 ${ }^{\text {eGFP/eGFP }}+$ Vit. C, AkrlA1 $1^{\text {eGFP/+ }}$ and WT groups (Figure 2E). These results showed that the

A

Chromosome 4D1

WT mice

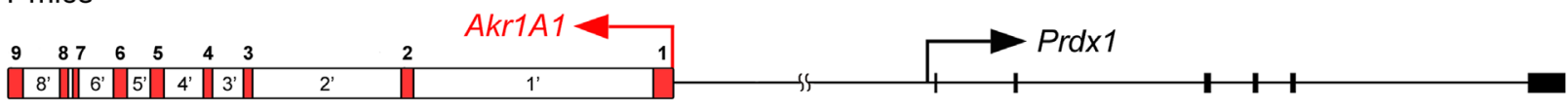

Akr1A1 $1^{\text {GFPleGFP mice }}$

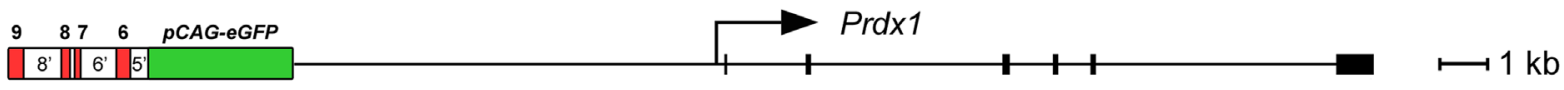

B

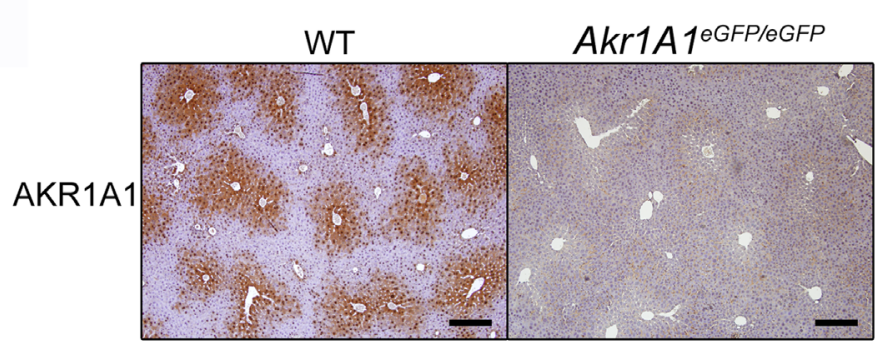

C

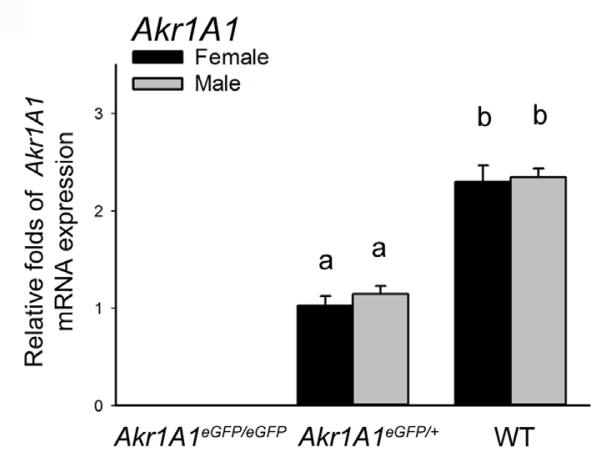

Figure 1: The characterization of the Akr1A1 KO mice. A. The $A k r l A l \mathrm{KO}$ mice were produced by microinjection, which the integration of the $p C A G-e G F P$ transgene (green) located in the chromosome 4D1 position, and caused the deletion of exon 1-5 (red), intron 1'-4' (white) of the AkrlAl gene and the non-coding nucleotides that between AkrlAl and Prdxl genes. Scale bar: 1 kb. B. The IHC analysis of AKR1A1 protein expressions in WT and $A k r l A l^{\text {GFP/eGFP }}$ mouse livers. The brown color indicated the AKR1A1 expressed hepatocytes. Scale bar: $400 \mu \mathrm{m}$. C. The $A k r 1 A 1 \mathrm{mRNA}$ expressions in $A k r 1 A 1^{\text {eGFP/eGFP }}, A k r 1 A 1^{\text {eGFP/+ }}$ and WT mouse livers. The values are represented as the mean $\pm \mathrm{SE}(n=6)$; data were analyzed by the one-way ANOVA with Duncan's new multiple range test; the significant differences $(P<0.05)$ are represented with different letters in all columns. 
A

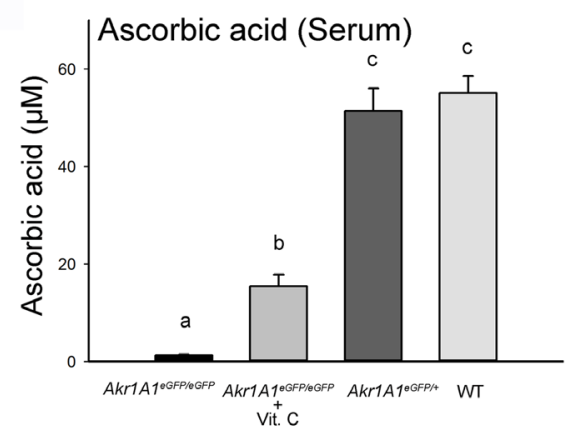

C

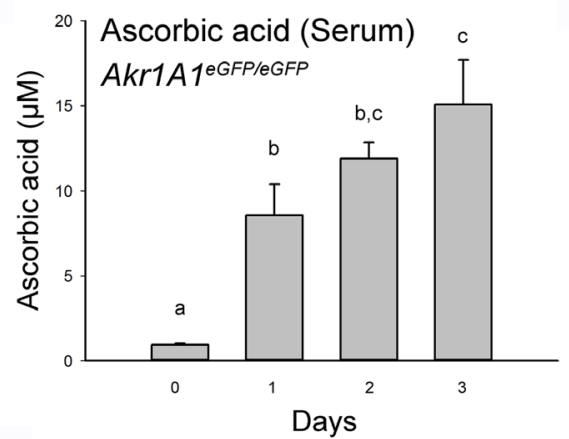

B

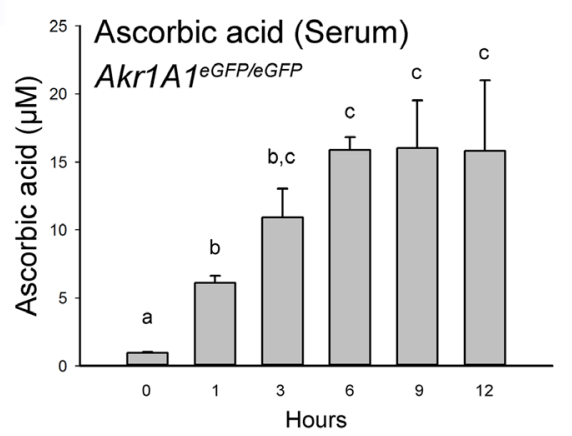

D

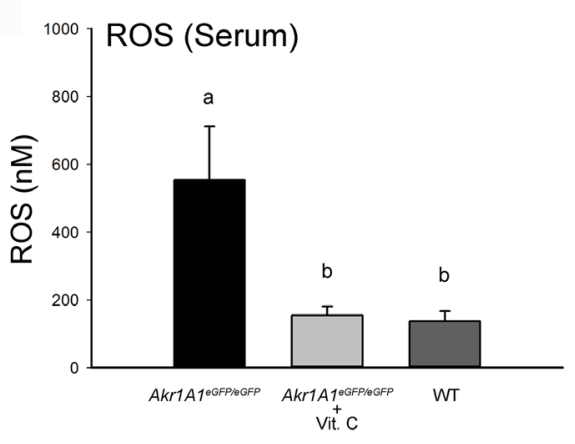

E

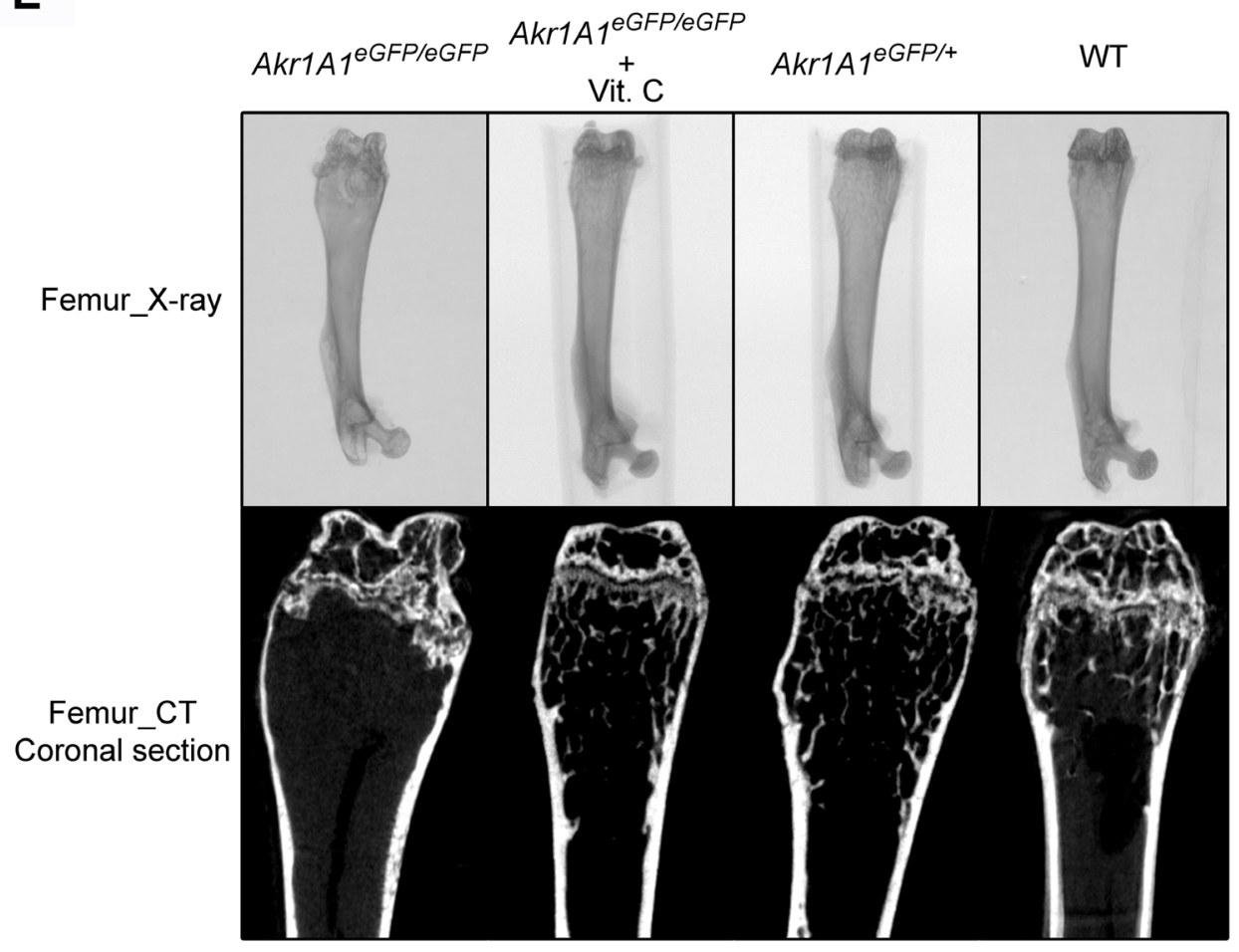

Figure 2: The absent of ascorbic acid, increased ROS and abnormal development of femurs in the Akr1A1 KO mice were prevented by ascorbic acid supplement. A. The ascorbic acid concentration in the blood serum of $A k r l A l^{\text {GGFPleGFP }}(n=6)$, $A k r l A l^{\text {eGFPleGFP }}$ with ascorbic acid supplement $(350 \mathrm{mg} / \mathrm{L})(\mathrm{n}=7), A k r 1 A l^{e G F P /+}(n=6)$ and WT $(\mathrm{n}=6)$ mice. B. and $\mathbf{C}$. The ascorbic acid concentration of blood serum in $A k r l A l^{\text {eGFPleGFP }}$ mice at different time points after the mice were fed with ascorbic acid $(350 \mathrm{mg} / \mathrm{L}) \mathrm{in}$ drinking water $(n=6)$. D. The ROS concentration in the serum of $A k r l A l^{\text {eGFP/CGFP }}(n=6), A k r l A l^{\text {eGFP/CGFP }}$ with ascorbic acid supplement $(350 \mathrm{mg} / \mathrm{L})(n=7)$ and WT $(n=6)$ mice. The values are represented as the mean \pm SE; data were analyzed by the one-way ANOVA with Duncan's new multiple range test. The bars with different letters represent $P<0.05$. E. The X-ray images and coronal sections of micro-CT analysis from the femurs of $A k r 1 A l^{\text {GGPP/CGFP }}, A k r l A l^{\text {eGFP/CGFP }}$ with ascorbic acid supplement $(350 \mathrm{mg} / \mathrm{L}), A k r 1 A l^{e G F P /+}$ and WT mice. 
Akr1A1 KO mice displayed abnormal bone development and severe osteoporosis even at a young age (12 weeks old).

\section{The micro-CT analysis of the trabecular and cortical bones in distal femurs}

To reveal the condition of the bone in $A k r 1 A 1$ $\mathrm{KO}$ mice, we used micro-CT to analyze and compare the microarchitecture of the femurs, which included the trabecular and cortical bone of the distal femur and the femoral head and neck of the proximal femur, among the $A k r l A 1^{e G F P / e G F P}, A k r l A 1^{e G F P / e G F P}+$ Vit. C, $A k r l A 1^{e G F P /+}$ and WT groups. The region that was $1.8 \mathrm{~mm}$ thick from the end of the epiphysis plate contained the most trabecular bones in the distal femurs of the WT mice, and the region that was $0.9 \mathrm{~mm}$ thick from the end of the trabecular bone selected region was used to construct and analyze the $3 \mathrm{D}$ structure of the trabecular and cortical bones (Figure 3A). The 3D structure showed that the number of trabecular bones in $A k r 1 A 1^{e G F P / e G F P}$ mice were severely reduced and that ascorbic acid supplementation could rescue trabecular bone formation (Figure 3B). Additionally, the 3D structure of the cortical bone revealed bone marrow cavity enlargement and cortical bone thinness in the $A k r l A 1^{e G F P /}$ eGFP mouse femur compared with the other groups (Figure 3C).

The micro-CT analysis that included bone volume (BV) / tissue volume (TV) and the numbers of trabecular bones (Tb.N) displayed results similar to the 3D structures
(Figure 4A and 4B). The measurements of trabecular bone separation (Tb.Sp) and thickness (Tb.Th) indicated that the spongy structures of the trabecular bone were not present in the AkrlAleGFP/eGFP mice (Figure $4 \mathrm{C}$ and 4D) and only thick trabecular bones were distributed around the edge of the bone marrow cavity (Figure $3 \mathrm{~B})$. Additionally, the measurement of the cortical bone revealed that the proportion of cortical bone volume (BV / TV) was reduced (Figure 4E) and the bone surface (BS) / BV and the diameter of the femur (Figure 4F and 4H) were increased in the $A k r l A 1^{\text {GFP/eGFP }}$ mice compared with the other groups. These data demonstrated that the decreased bone volume and the increased surface area both resulted in increased weight loading per $\mathrm{mm}^{2}$ of the cortical bone in the $A k r l A 1^{\text {eGFP/eGFP }}$ mice. In addition to the quantity of cortical bones, the quality of the cortical bone was also evaluated according to the BMD. The results showed that the BMD of cortical bones was also reduced in the $A k r l A 1^{\text {eGFP/eGFP }}$ mice compared with the other groups (Figure 4G). These results indicated that reduced formation and strength of the trabecular bones in the femurs of the $A k r l A 1^{\text {eGFP/eGFP }}$ mice compared with the $A k r l A 1^{e G F P / e G F P}+$ Vit. C and $A k r 1 A 1^{e G F P /+}$ groups.

\section{The micro-CT analysis of proximal femurs}

Proximal femur fractures comprise nearly $20 \%$ of all osteoporotic fractures in humans. Therefore, the bone quality of the proximal femur, including the femoral head and neck, are important factors for evaluating
A

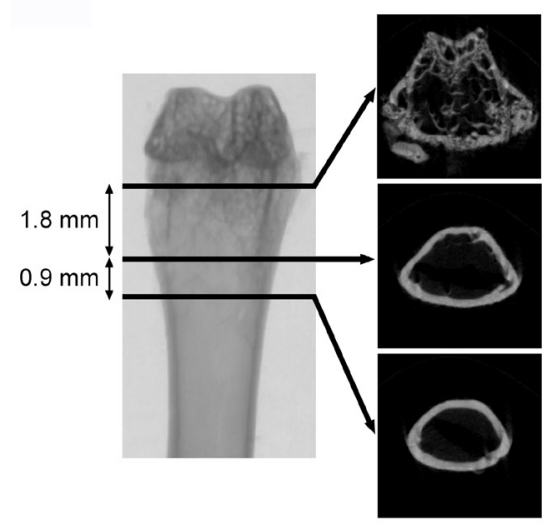

B

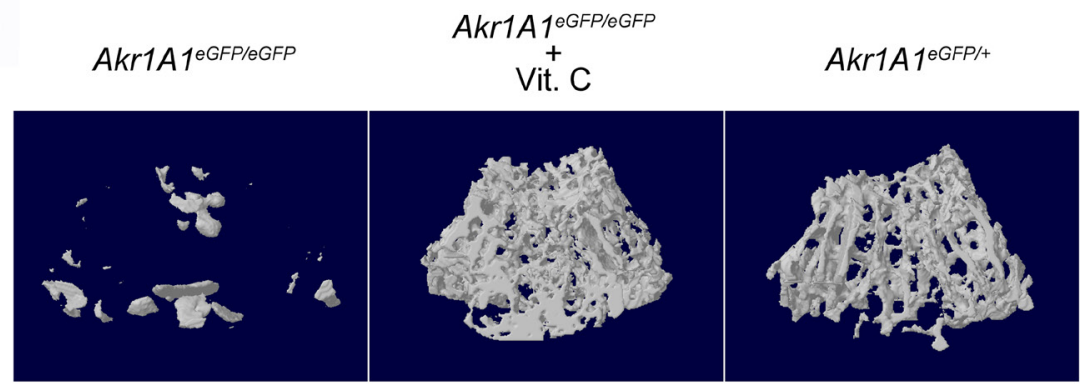

C

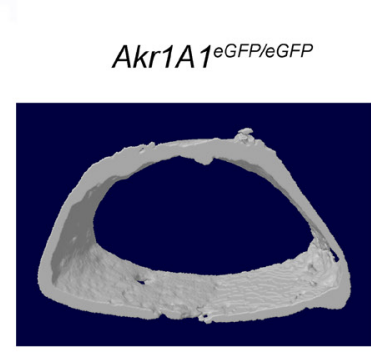

Akr1A1 $1^{\text {GFP/OGFP }}$

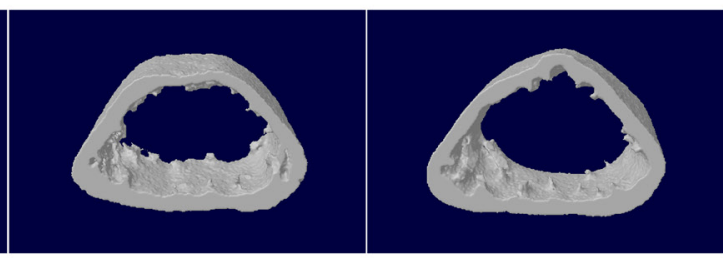
Vit. C Akr1A1 ${ }^{\text {eGFP/+ }}$

Figure 3: The 3D structure of trabecular and cortical bones in the distal femurs. A. The micro-CT analyzed region of the femurs where the 1.8 and $0.9 \mathrm{~mm}$ regions were used to construct the 3D structure of trabecular and cortical bones, respectively. The femur sections showed the structures of upper and lower boundary of the analyzed regions. B. and $\mathbf{C}$. The structures of trabecular and cortical bones in the distal femurs of $A k r 1 A 1^{\text {eGFP/eGFP }}, A k r 1 A 1^{\text {GFP/eGFP }}$ with ascorbic acid supplement and $A k r 1 A 1^{e G F P /+}$ mice. 
osteoporosis. To examine the osteoporotic condition of femoral head and neck through micro-CT imaging, the femoral head and neck were aligned with the $X-Z$ axial plane of the femur, and $\mathrm{X}-\mathrm{Z}, \mathrm{Y}-\mathrm{Z}$ and $\mathrm{X}-\mathrm{Y}$ sections were used to reveal the proximal femur structures (Figure 5A). The results showed that the bone mass in the femoral head and neck was reduced in the $A k r l A 1^{\text {GFP/GFP }}$ mice and that the femoral neck cavity was enlarged and the trabecular structure was decreased in the femoral head compared with the other groups (Figure 5B, 5C and 5D).

\section{Osteoporosis in the $A k r 1 A 1 \mathrm{KO}$ mice was caused by insufficient bone formation}

The occurrence of most osteoporosis was due to imbalanced bone metabolism. To evaluate the causes of osteoporosis in the $A k r 1 A 1 \mathrm{KO}$ mice, the osteoblast and osteoclast activities and the osteoporosis markers in the blood serum were analyzed. Using a colony-forming unitosteoblast (CFU-OB) assay, the active osteoblast area of the bone marrow cell culture was found to be reduced in the $A k r l A 1^{\text {GFP/eGFP }}$ group compared with the $A k r l A 1^{\text {eGFP/+ }}$ group, and the area of the $A k r l A 1^{\text {eGFP/eGFP }}+$ Vit. C group was slightly increased compared with that of the AkrlA1 $1^{\text {eGFP/eGFP }}$ group (Figure 6A and 6B). Osteocalcin is the most abundant non-collagenous protein in bone matrix. It is produced by osteoblasts and some osteocalcin is released into circulation during bone formation. Therefore, the serum osteocalcin level was used to evaluate the activity of bone formation [20]. The serum osteocalcin level in these three groups also showed similar results with that of the CFU-OB assay (Figure 6C). Additionally, using an in vitro osteoclast formation assay, the results showed that there was no significant difference in the number of active osteoclasts in the bone marrow cell culture among the three groups (Figure 6D and 6E); the C-terminal telopeptide of collagen I (CTX-I) of blood serum, which was used as a specific marker for the activity of bone resorption [21], also showed a similar result (Figure 6F). These results may imply that the activity of osteoblasts and bone formation rather osteoclasts and bone resorption were responsible for the osteoporosis in the $A k r l A 1 \mathrm{KO}$ mice.

\section{DISCUSSION}

During the generation of the $p C A G$-eGFP transgenic mice via pronuclear microinjection, the $A k r l A 1$ gene was disrupted by the integration of the transgene and thus completely abolished the gene expression (Figure 1). AKR1A1 is involved in the major portion (85\%) of the catalysis that converts D-glucuronate to L-gulonate in the synthetic pathway $[17,22]$. The $A k r 1 A 1 \mathrm{mRNA}$ expression in the $A k r l A 1^{e G F P /+}$ mice exhibited a $50 \%$ reduction compared to WT mice (Figure 1C); however, the serum ascorbic acid concentration was the same in the $A k r 1 A 1^{e G F P /+}$ and WT mice but was nearly eliminated in the $A k r 1 A 1^{e G F P / e G F P}$ mice (Figure 2A). These results suggest that less than $50 \%$ of $A k r 1 A 1$ expression in mice is sufficient for ascorbic acid synthesis.

Osteoporosis of the femur was the marked phenotype of the AkrlAl KO mice. The consequences
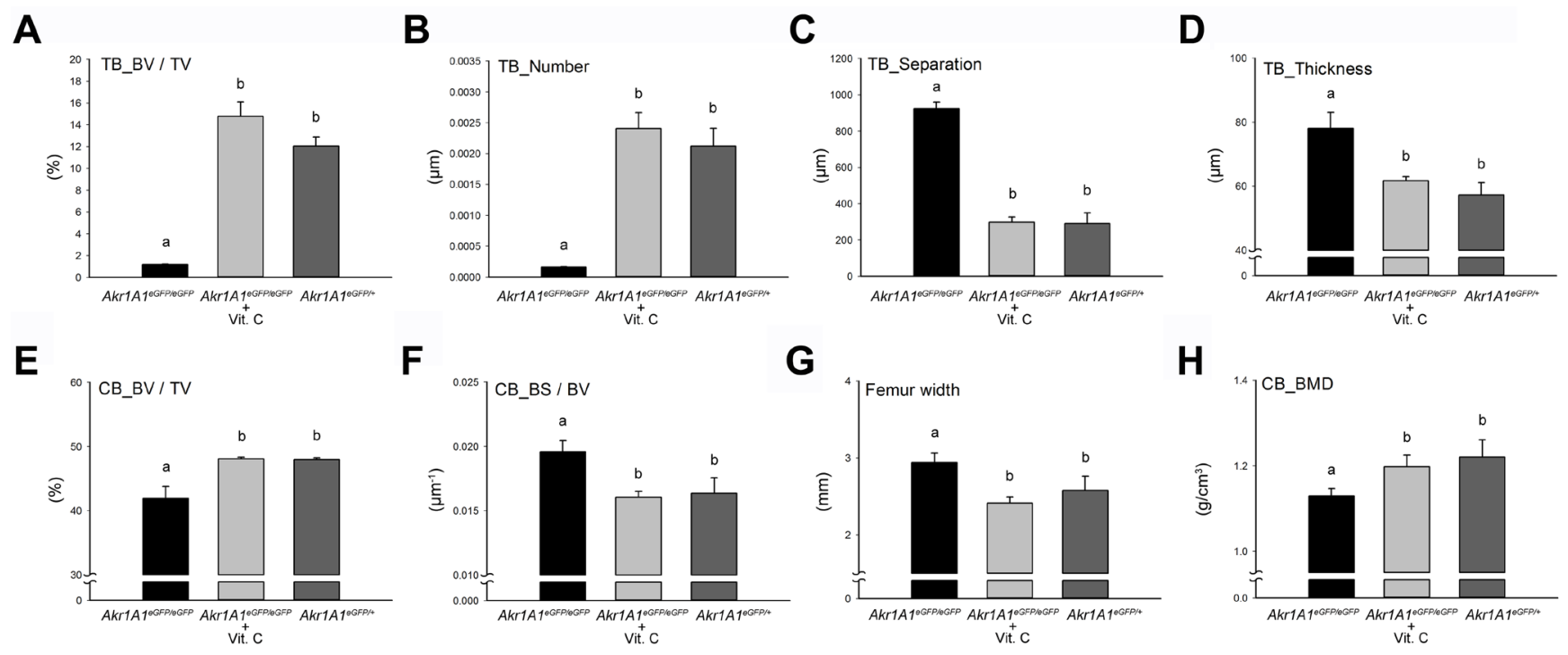

Figure 4: The micro-CT analytic scores of trabecular and cortical bones of the distal femurs. The trabecular bone (TB) scores of bone volume (TB_BV/TV) A., trabecular number (Tb.N) B., trabecular separation (Tb.Sp) C. and trabecular thickness (Tb.Th) D., and the cortical bone $(\overline{C B})$ scores of bone volume (CB_BV/TV) E., bone surface (CB_BS/BV) F., femoral width $\mathbf{G}$. and bone mineral density (CB_BMD) H. in the regions, which were showed in Figure $3 \mathrm{~B}$ and $3 \mathrm{C}$, of $A k r 1 A l^{\text {eGFP/eGFP }}(n=6), A k r 1 A 1^{\text {eGFP/eGFP }}$ with ascorbic acid supplement $(n=6)$ and $A k r l A 1^{e G F P /+}(n=6)$ mouse femurs. The values are represented as the mean \pm SE; data were analyzed by the one-way ANOVA with Duncan's new multiple range test. The bars with different letters represent $P<0.05$. 
of the osteoporosis included severe trabecular bone loss, decreased BMD, cortical bone thickness and bone marrow cavity enlargement in the distal femur. Moreover, the bone mass of the femoral head and neck in the proximal femur of the $A k r 1 A 1 \mathrm{KO}$ mice was also decreased compared with the $A k r l A 1^{e G F P /+}$ and $A k r l A 1^{e G F P / e G F P}$ mice supplied with ascorbic acid. According to the water intake of the mice (6-12 mL/day) [23] and the ascorbic acid concentration supplied via the drinking water $(350 \mathrm{mg} / \mathrm{L})$, the ingested dosage of the mice in the $A k r l A l^{\text {eGFP/GFP }}+$ Vit. C group was 2.1-4.2 $\mathrm{mg}$ per day, and this dosage was recommended for the maintenance of other ascorbic aciddeficient mouse colonies (Gulo KO mice) [24,25]. Based on the measurement of serum ascorbic acid in the mice, the ascorbic acid level in the AkrlA1 $1^{\text {eGFP } / e G F P}+$ Vit. C group was only $\sim 1 / 4$-fold of that in the $A k r 1 A 1^{e G F P /+}$ and WT groups (Figure 2A); however, the ROS levels and the femur structures were identical to the WT and $A k r l A 1^{e G F P /+}$ groups (Figure 2D and 2E). This result demonstrated that the ascorbic acid supplement in the present study was sufficient to maintain oxidative stress in the normal range and was also sufficient to rescue the osteoporosis phenotype in the $A k r 1 A 1 \mathrm{KO}$ mice. Moreover, the identical ascorbic acid levels and the architecture of the femurs between the $A k r 1 A 1^{e G F P /+}$ and WT mice indicate that the $A k r l A 1^{e G F P /+}$ mice may provide a better control group that
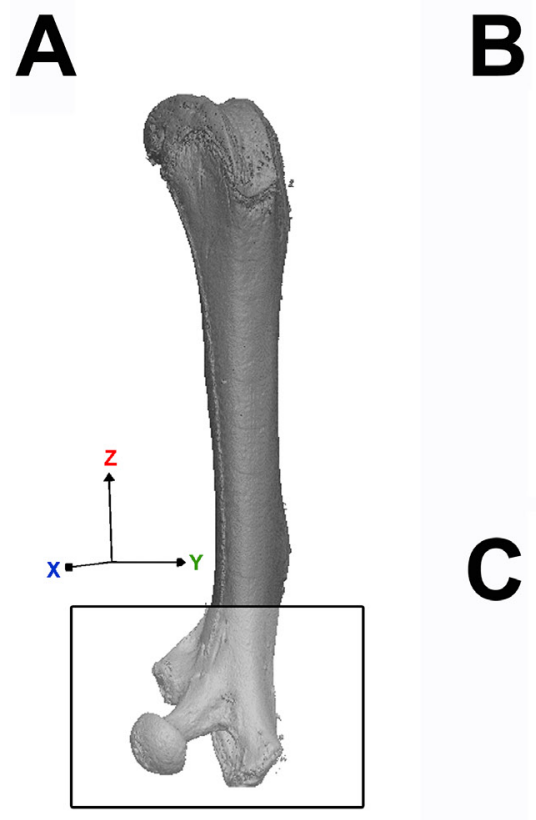

Akr1A1 $1^{\text {GFP/EGFP }}$
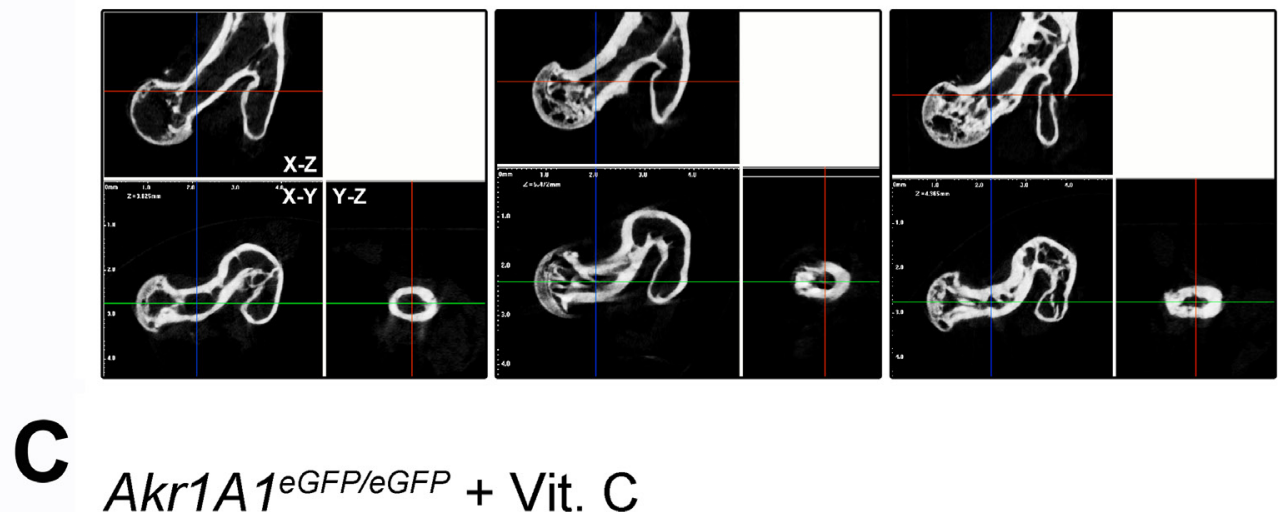

Akr1A1 $1^{\text {GFP/EGFP }}+$ Vit. C
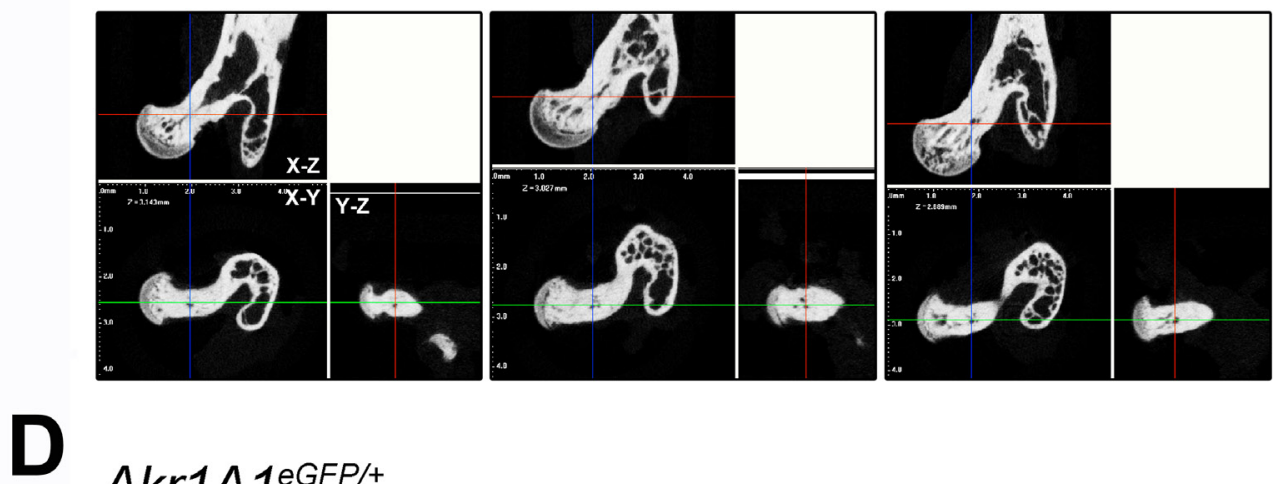

$A k r 1 A 1^{\mathrm{GFP} /+}$
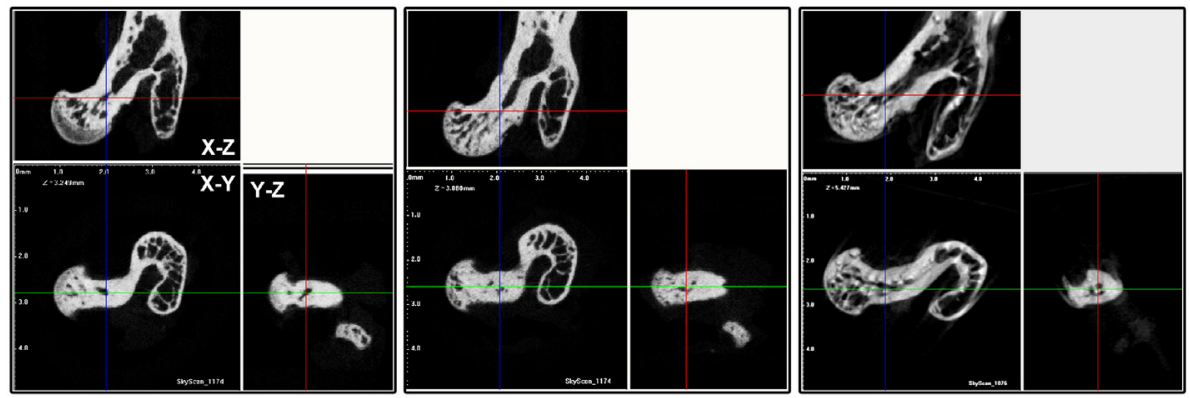

Figure 5: The structures of femoral head and neck at the proximal femurs. A. The micro-CT analyzed region of femoral head and neck at the proximal femur (the square region). The X, Y, Z axis represented the orientation of the femur. B., C. and D. The sections of the X-Z, X-Y and Y-Z axial planes of the proximal femurs in AkrlAleGFP/GFP,$A k r 1 A 1^{\text {EGFP/CGFP }}$ with ascorbic acid supplement and $A k r l A 1^{e G F P /+}$ mice, respectively, and the results were showed in triplicate. 
A

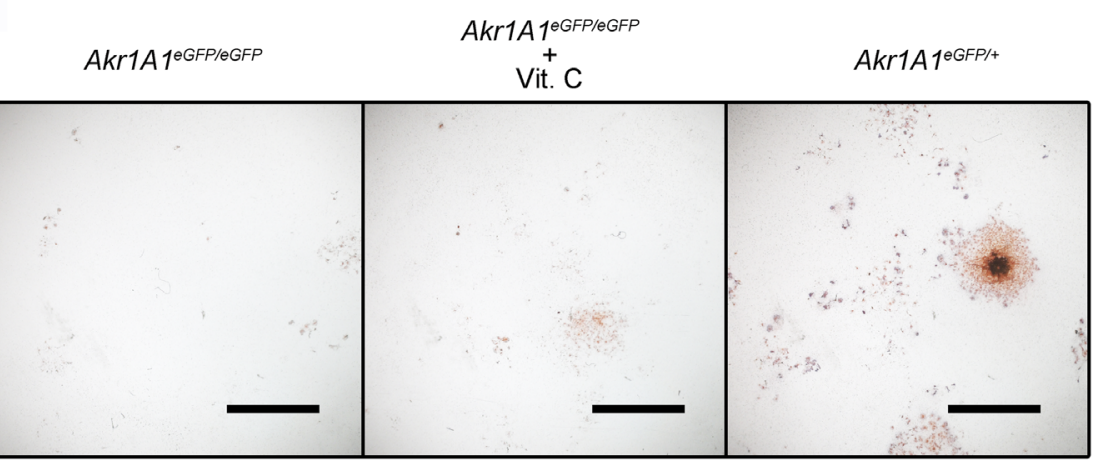

B

C
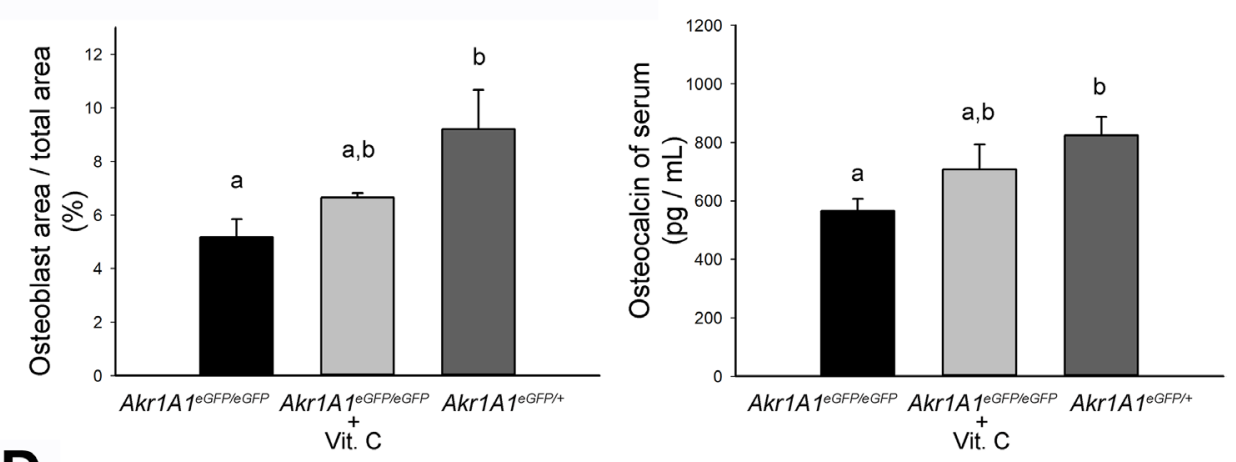

D

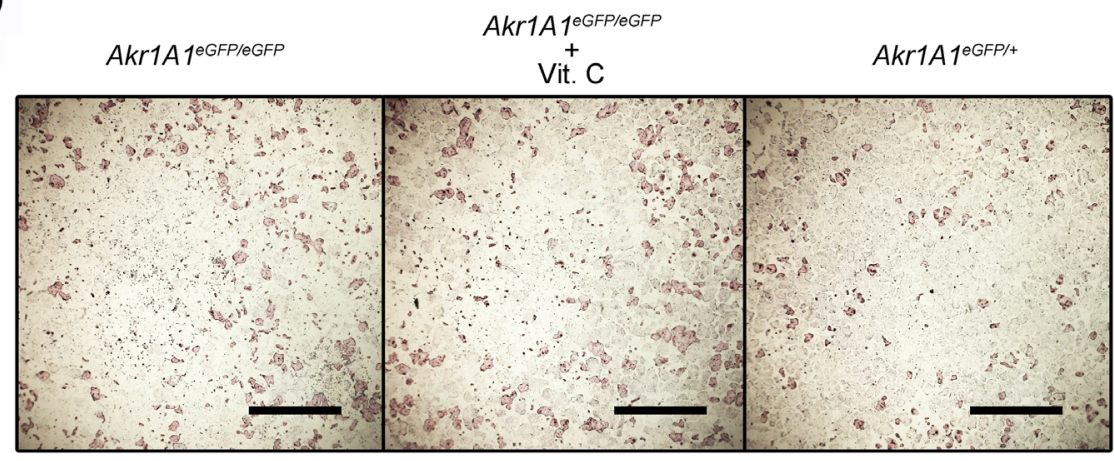

$\mathbf{E}$

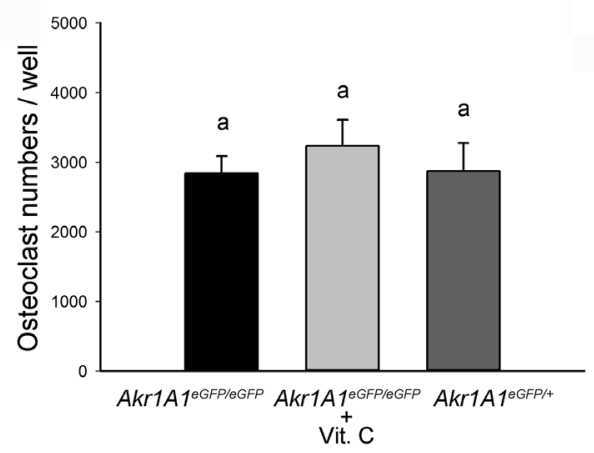

$\mathbf{F}$

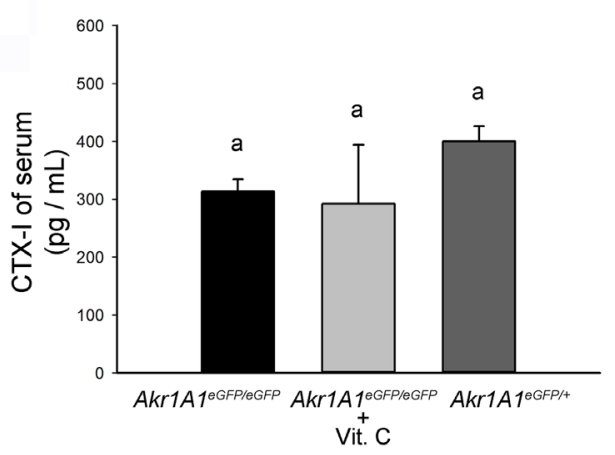

Figure 6: The decreased osteoblast number and bone formation in the Akr1A1 KO mice. A. and B. The CFU-OB assay of $A k r l A 1^{\text {eGFP/eGFP }}(n=6), A k r l A 1^{\text {eGFP/CGFP }}$ with ascorbic acid supplement $(n=6)$ and $A k r l A l^{\text {eGFP/+ }}(n=6)$ mouse femurs and the osteoblast area in $35 \mathrm{~mm}$ culture dishes. $\mathbf{C}$. The quantification of bone formation marker, osteocalcin, in the groups. D. and $\mathbf{E}$. The in vitro osteoclast formation assay of $A k r 1 A 1^{e G F P / G F P}(n=6), A k r l A 1^{e G F P / C G F P}$ with ascorbic acid supplement $(n=6)$ and $A k r l A l^{e G F P /+}(n=6)$ mouse femurs and the osteoclast numbers in $35 \mathrm{~mm}$ culture dishes. F. The quantification of bone resorption marker, CTX-I, in the groups. Scale bar: 0.5 $\mathrm{mm}$. The values are represented as the mean $\pm \mathrm{SE}$; data were analyzed by the one-way ANOVA with Duncan's new multiple range test. The bars with different letters represent $P<0.05$. 
avoids the variation between the inbred transgenic colony and the WT mice.

Ascorbic acid is known to be important for the formation and maintenance of bone mass [17, 26], but the detailed mechanisms involved in these processes are still unknown. A previous study showed that the bone formation marker osteocalcin was decreased in Gulo KO mice after 3-4 weeks of ascorbic acid withdrawal compared with WT mice [27]. In the present study, similar results were also observed in the $A k r 1 A 1 \mathrm{KO}$ mice in which ascorbic acid was deficient since birth (Figure 6C). However, there was no significant difference in the levels of the bone resorption marker CTX-I between the $A k r 1 A 1^{e G F P / e G F P}+$ Vit. C and $A k r l A 1^{e G F P /+}$ groups (Figure $6 \mathrm{~F}$ ). These results suggested that the osteoporosis in the AkrlAleGFP/eGFP mice was due to insufficient bone formation possibly due to deficient ascorbic acid production.

Vitamin $\mathrm{C}$ has been shown to exert positive effects on differentiating mouse embryonic stem (ES) cell, bone marrow stromal cell line, calvaria-derived cells or osteoblast-like cells to become osteoblasts [28,29]. In addition, previous studies showed that Vit. C-treated osteoblast-like cells may activate osterix [30] or prolyl hydroxylase domain (PHD) [31] gene transcription at the early stage of osteoblast differentiation and then stimulates initial deposition of collagen followed by induction of specific genes associated with the osteoblast phenotype [32,33]. Furthermore, Vit. C-treated osteoblasts also up-regulated osteogenic growth factors, including transforming growth factor (TGF)- $\beta$, estrogen receptor (ER)- $\alpha$ and osteopontin which stimulated bone formation [34].

In humans, insufficiency of ascorbic acid intake has been known to increase the risk of osteoporosis and fracture $[13,35,36]$. Epidemiological studies have shown that there is an increased prevalence of osteopenia and osteoporosis in premenopausal women from impoverished areas where the people consume an insufficient Vit. $\mathrm{C}$ from fruits and vegetables [37]. Moreover, current smoking behavior, which increases the amount of free radicals, was shown to decrease the BMD of the femoral neck in the non-ascorbic acid supplement group [13]. In these cases, inadequate peak bone mass due to malnutrition or other factors that influence bone formation resulted in the development of osteoporosis without the occurrence of accelerated bone loss. In the present study, ascorbic acid administration was able to control the osteoporotic status of the $A k r 1 A 1 \mathrm{KO}$ mice according to ascorbic acid supplementation and withdrawal during development. Therefore, the mice might represent a unique osteoporosis model in which the osteoporosis is caused by insufficient peak bone mass at a young age, which is distinguished from the hypogonadism-induced bone loss that was commonly used as the osteoporosis model for postmenopausal women and elderly people [38].
Vitamin C deficiency increased cancer occurrence and shortened survival in murine model [39] and patients [40]. Previous studies demonstrated that Vit. C supplementation obviously reduced the breast cancerspecific death [41] and prostate cancer occurrence [42]. High-dose Vit. C administration also inhibited the proliferation of cancer cells, and induced tumor cell apoptosis in mouse model in vitro and in vivo [43]. In addition, Vit. $\mathrm{C}$ deficiency increased the progression of murine melanoma and breast cancer cells xenografts in $\mathrm{Gulo}^{-/-} \mathrm{KO}$ mice, while supplementation of Vit. C inhibited metastasis, tumor growth and inflammatory cytokine secretion in tumor-engrafted Gulo $^{-/} \mathrm{KO}$ mice $[39,44]$. Similar to Gulo $^{-/-} \mathrm{KO}$ mice, aldo-keto reductases (AKRs) knockout mice also become scorbutic without Vit. C supplementation, but this model has not yet been studied in cancer research [39]. Currently, the roles of AKRs in tumorigenesis have been reported, such as Goh et al. [45] found that AKR1A1 protein expression was significantly decreased in hepatocellular carcinoma.

In summary, AkrlAl KO mice presented with a reduction in ascorbic acid production and an increased level of ROS in the serum and, consequently, showed insufficient trabecular and cortical bone mass of the femur at a young age. Through in vivo or ex vivo micro$\mathrm{CT}$ analysis, the knockout mice may serve as a useful model to mimic the development of osteoporosis due to sub-optimal bone growth rather than accelerated bone resorption during childhood and adolescence.

\section{MATERIALS AND METHODS}

\section{Animals}

The animals used in this study were approved by the Institutional Animal Care and Use Committee (IACUC No.: 103-97) of National Chung Hsing University. The male and female $A k r 1 A 1 \mathrm{KO}$ mice $\left(A k r 1 A 1^{\text {GFP/eGFP }}\right.$ ) that contain the genetic background of the CD-1 mouse strain were generated by pronuclear microinjection [46], and a $p C A G-e G F P$ vector was double digested with SalI and HindIII and used as a transgene. The AkrlAl gene knockout was the result of an integration of the transgene and the results were confirmed using compatible ends ligation inverse-PCR (CELI-PCR) [15], quantitative RTPCR (Q-PCR) and immunohistochemistry (IHC). The originally produced male and female founder mice (F0) were bred with wild-type (WT) CD-1 mice for at least 2 generations to avoid multiple integrations of the transgene [47].

The female mice in the following biochemical and osteoporotic analyses were divided into 4 groups, $A k r 1 A 1^{e G F P / e G F P}, A k r 1 A 1^{e G F P / e G F P}+$ Vit. C, AkrlA1 $1^{e G F P /+}$ and WT. In the $A k r 1 A 1^{e G F P / e G F P}+$ Vit. C group, the mice 
were supplemented with ascorbic acid (350 mg/L; SigmaAldrich, St. Louis, MO, USA) in drinking water since the day of birth, and the fresh prepared ascorbic acid containing water was changed 2 times a week. All of the mice were fed with a regular diet lacking ascorbic acid until 12 weeks of age. At the end of the 12 th week, the mice were sacrificed, and the blood serums and femoral bones were isolated for later analysis.

\section{Immunohistochemistry (IHC)}

The liver tissues, which were obtained from anesthetized WT or AkrlAleGFP/eGFP mice, were immediately fixed using $10 \%$ formalin for at least $16 \mathrm{~h}$. The $3 \mu \mathrm{m}$ paraffin-embedded sections of fixed liver were used for immunostaining of the AKR1A1 protein. Briefly, the sections were deparaffinized by $100 \%$ xylene and rehydrated by a series of ethanol washes $(100 \%, 90 \%$, $80 \%$ and $60 \%$ ), and the antigens were then retrieved using retrieval buffer (10 mM sodium citrate, $0.05 \% \mathrm{NP}-40, \mathrm{pH}$ 6.0 ) at $95{ }^{\circ} \mathrm{C}$ for $30 \mathrm{~min}$. The sections were incubated with $3 \% \mathrm{H}_{2} \mathrm{O}_{2}$ for $10 \mathrm{~min}$ to block the endogenous peroxidase activity, and horse serum for $30 \mathrm{~min}$ and then incubated with polyclonal rabbit anti-AKR1A1 (1:500; SigmaAldrich) at $4{ }^{\circ} \mathrm{C}$ for $16 \mathrm{~h}$. The AKR1A1 protein signal was amplified using the Elite ABC Kit (Vector Labs., Burlingame, CA, USA). Finally, the sections were stained with 3,3'-diaminobenzidine (DAB) and counterstained with hematoxylin $[48,49]$. The images of the sections were observed and captured using the Zeiss Axio Scope. A1 microscope (Zeiss, Germany).

\section{Quantitative RT-PCR (Q-PCR)}

Total RNA was isolated from the $A k r l A 1^{e G F P /}$ ${ }^{e G F P}, A k r 1 A 1^{e G F P /+}$, and WT mouse livers using TRIzol reagent (Invitrogen Corp., Grand Island, NY, USA) according to the manufacturer's instructions. The $1 \mu \mathrm{g}$ of the total RNA was used for the first-strand cDNA synthesis by the ImProm-II Reverse Transcription System (Promega, Madison, WI, USA). The AkrlA1 mRNA expressions were analyzed using the relative standard curve method, and the mRNA expressions of $\beta$-actin gene were used as an internal control [50]. The reactions were performed with the $A k r l A 1$ forward primer 5'-CAACTGGAGTATTTGGACCTC-3' and reverse primer 5'-GACATCATCAATCTGCCGAC-3'. The PCR conditions were $95^{\circ} \mathrm{C}$ for $2 \mathrm{~min}, 40$ cycles of $95^{\circ} \mathrm{C}$ for 30 sec, $56^{\circ} \mathrm{C}$ for $30 \mathrm{sec}$ and $72{ }^{\circ} \mathrm{C}$ for $20 \mathrm{sec}$, and followed by a $65^{\circ} \mathrm{C}$ to $95^{\circ} \mathrm{C}$ melting step.

\section{The quantitative measurement of ascorbic acid, ROS, osteocalcin and CTX-I in serum}

After anesthetization, the mouse blood was isolated by cardiac puncture, then the blood was centrifuged by $3000 \mathrm{rpm}$ for $10 \mathrm{~min}$ to separate the serum from blood cells, and stored at $-80{ }^{\circ} \mathrm{C}$ until use. The concentration of ascorbic acid, ROS, osteocalcin [51] and CTX-I [52] in the serum were measured by Ascorbic Acid Assay Kit (Abcam, Cambridge, MA, USA), OxiSelect ${ }^{\mathrm{TM}}$ In Vitro ROS/RNS Assay Kit (Cell Biolabs, Inc., San Diego, CA, USA) and enzyme-linked immunosorbent assay (ELISA) (Cloud-Clone Corp., Houston, TX, USA), respectively, according to the instruction manuals.

\section{Micro-CT analysis of femur}

The femurs from 12-week-old mice of the experimental groups were fixed in $10 \%$ formalin for 24 hours, and then X-ray micro-CT was performed by Skyscan 1076 machine (Bruker microCT, Kontich, Belgium) with $9 \mu \mathrm{m}$ resolution [53]. The raw data was analyzed according to the standard procedure [54]. Briefly, the scanning results were first reconstructed into 2D model by NRecon software (Bruker microCT). Then, according to the region of interesting (ROI) selection of the femurs, the characters of the trabecular and cortical bone were analyzed by CTAn software (Bruker microCT), and $3 \mathrm{D}$ model of the ROI region were constructed by CTvol software (Bruker microCT). The ROI of trabecular bone was selected for $1.8 \mathrm{~mm}$ thick that was started from the epiphysis plate in distal femur (Figure 3A), and the microarchitecture of the trabecular bones were analyzed. Trabecular bone volume (BV/TV) was calculated using bone volume (BV) and total tissue volume (TV). Mean trabecular thickness (Tb.Th) was determined based on the local thickness. Trabecular separation (Tb.Sp) and trabecular number (Tb.N) were estimated using the plate model. The ROI of the cortical bone were selected for $0.9 \mathrm{~mm}$ thick followed by the ROI of trabecular bone (Figure 3A), and the characters of the cortical bones were analyzed, including: BV/TV, BS / BV, BMD and femur width.

\section{Colony forming unit-osteoblast (CFU-OB) assay}

The unattached bone marrow cells obtained from the $A k r l A 1^{\text {eGFP/eGFP }}, A k r l A 1^{\text {eGFP/eGFP }}$ with ascorbic acid supplement and $A k r 1 A 1^{e G F P /+}$ mouse femurs, and the cells were cultured with $\alpha$-MEM containing $10 \% \mathrm{FBS}, 50 \mu \mathrm{g} /$ $\mathrm{ml} \mathrm{L-ascorbic} \mathrm{acid} \mathrm{and} 10 \mathrm{mM} \beta$-glycerophosphate in 35 $\mathrm{mm}$ culture dish with the density of $2.5 \times 10^{6}$ cells per dish [55]. The medium was changed every 3 days. At the end of the 28th day, the cells were stained with ALP staining 
kit (Sigma-Aldrich) according to the instruction manual and the images were captured under anatomic microscope.

\section{In vitro osteoclast formation assay}

The unattached bone marrow cells obtained from the AkrlA1 ${ }^{\text {eGFPleGFP }}, A k r l A 1^{\text {eGFPleGFP }}$ with ascorbic acid supplement and $A k r 1 A 1^{e G F P /+}$ mouse femurs, and the cells were cultured with $\alpha$-MEM containing $10 \%$ FBS, $50 \mathrm{ng} / \mathrm{ml}$ RNAKL and $25 \mathrm{ng} / \mathrm{ml} \mathrm{M}$-CSF in $35 \mathrm{~mm}$ culture dish with the density of $2.5 \times 10^{6}$ cells per dish [56]. The medium was changed every 3 days. At the end of the 14th day, the cells were stained with TRAP staining kit (Sigma-Aldrich) according to the instruction manual and the images were captured under anatomic microscope.

\section{Statistical analysis}

All data were presented as the mean \pm standard error of mean (SE). The Student's $t$-test and the one-way ANOVA with Duncan's new multiple range test were used for the comparisons of two and multiple groups, respectively. A $P$-value $<0.05$ was considered significant.

\section{ACKNOWLEDGMENTS}

The authors would like to thank our colleagues (Drs. Yu-Tang Tung and Tung-Chou Tsai) in the Molecular Embryology \& DNA Methylation Laboratory for their help with discussions and technical issues. We also thank the Center for Advanced Molecular Imaging and Translation (Chang Gung Memorial Hospital-Linkou, Taoyuan, Taiwan) and the SPF Animal Center Animal Image Laboratory Chang Gung University for molecular Imaging service. This research was supported in part by grants MOST-104-2313-B-005-043-MY3, MOST 104-2320-B-182-020-MY3 and MOST 105-2314-B-182042-MY3 from the Ministry of Science and Technology; CMRPD-1B-0473 and CMRPD-1E-0231 from Chang Gung Memorial Hospital Grant; and grant ATU105-S0508 from the Ministry of Education, Taiwan, under the Aiming for Top University plan. The funders had no role in the study design, data collection and analysis, decision to publish, or preparation of the manuscript.

\section{CONFLICTS OF INTERESTS}

The authors have declared that there are no conflicts of interest..

\section{Author contributions}

C.M.C. and H.L.C. designed the experiments. C.W.L., M.Y.T., T.R. and W.Y.L. performed the experiments. H.L.C., M.Y.T., K.Y.C. and C.M.C. performed data analysis. C.W.L., S.H.Y. Y.W.L. and C.M.C. prepared the manuscript and figures. C.M.C. and K.Y.C. provided project leadership. All authors contributed to the final manuscript.

\section{REFERENCES}

1. National Institutes of Health of United States (NIH). Osteoporosis prevention, diagnosis, and therapy. NIH Consens Statement. 2000;17: 1-45.

2. Bernabei R, Martone AM, Ortolani E, Landi F, Marzetti E. Screening, diagnosis and treatment of osteoporosis: a brief review. Clin Cases Miner Bone Metab. 2014;11: 201-207.

3. Lin YC, Pan WH. Bone mineral density in adults in Taiwan: results of the Nutrition and Health Survey in Taiwan 20052008 (NAHSIT 2005-2008). Asia Pac J Clin Nutr 2011;20: 283-291.

4. Silva BC, Bilezikian JP. Trabecular bone score: perspectives of an imaging technology coming of age. Arq Bras Endocrinol Metabol. 2014;58: 493-503.

5. Kanis JA, Devogelaer JP, Gennari C. Practical guide for the use of bone mineral measurements in the assessment of treatment of osteoporosis: a position paper of the European foundation for osteoporosis and bone disease. The Scientific Advisory Board and the Board of National Societies. Osteoporos Int. 1996;6: 256-261.

6. Eriksen EF. Cellular mechanisms of bone remodeling. Rev Endocr Metab Disord. 2010;11: 219-227.

7. Farr JN, Khosla S. Skeletal changes through the lifespanfrom growth to senescence. Nat Rev Endocrinol. 2015;11: 513-521.

8. Chapurlat RD. Odanacatib: a review of its potential in the management of osteoporosis in postmenopausal women. Ther Adv Musculoskelet Dis. 2015;7: 103-109.

9. Huang W, Yang S, Shao J, Li YP. Signaling and transcriptional regulation in osteoblast commitment and differentiation. Front Biosci. 2007;12: 3068-3092.

10. Soltanoff CS, Yang S, Chen W, Li YP. Signaling networks that control the lineage commitment and differentiation of bone cells. Crit Rev Eukaryot Gene Expr. 2009;19: 1-46.

11. Chen G, Deng C, Li YP. TGF- $\beta$ and BMP signaling in osteoblast differentiation and bone formation. Int J Biol Sci. 2012;8: 272-288.

12. van de Peppel J, van Leeuwen JP. Vitamin D and gene networks in human osteoblasts. Front Physiol. 2014;5: 137.

13. Sahni S, Hannan MT, Gagnon D, Blumberg J, Cupples LA, Kiel DP, et al. High vitamin C intake is associated with lower 4-year bone loss in elderly men. J Nutr. 2008;138: 1931-1938.

14. Simon JA, Hudes ES. Relation of ascorbic acid to bone mineral density and self-reported fractures among US adults. Am J Epidemiol. 2001;154: 427-433.

15. Ren M, Chen Q, Li L, Zhang R, Guo S. Successive 
chromosome walking by compatible ends ligation inverse PCR. Mol Biotechnol. 2005;30: 95-102.

16. Faucher F, Jia Z. High-resolution structure of AKR1a4 in the apo form and its interaction with ligands. Acta Crystallogr Sect F Struct Biol Cryst Commun. 2012;68: 1271-1274.

17. Gabbay KH, Bohren KM, Morello R, Bertin T, Liu J, Vogel P. Ascorbate synthesis pathway: dual role of ascorbate in bone homeostasis. J Biol Chem. 2010;285: 19510-19520.

18. Fukumura H, Sato M, Kezuka K, Sato I, Feng X, Okumura $\mathrm{S}$, et al. Effect of ascorbic acid on reactive oxygen species production in chemotherapy and hyperthermia in prostate cancer cells. J Physiol Sci. 2012;62: 251-257.

19. Thompson DD, Simmons HA, Pirie CM, Ke HZ. FDA Guidelines and animal models for osteoporosis. Bone. 1995; 17: 125S-133S.

20. Kanbur NO, Derman O, Sen TA, Kinik E. Osteocalcin. A biochemical marker of bone turnover during puberty. Int $\mathrm{J}$ Adolesc Med Health. 2002;14: 235-244.

21. Henriksen K, Flores C, Thomsen JS, Brüel AM, Thudium CS, Neutzsky-Wulff AV, et al. Dissociation of bone resorption and bone formation in adult mice with a nonfunctional V-ATPase in osteoclasts leads to increased bone strength. PLoS One. 2011;6: e27482.

22. Jez JM, Flynn TG, Penning TM. A new nomenclature for the aldo-keto reductase superfamily. Biochem Pharmacol. 1997;54: 639-647.

23. Bachmanov AA, Reed DR, Beauchamp GK, Tordoff MG. Food intake, water intake, and drinking spout side preference of 28 mouse strains. Behav Genet. 2002;32: 435-443.

24. Maeda N, Hagihara H, Nakata Y, Hiller S, Wilder J, Reddick R. Aortic wall damage in mice unable to synthesize ascorbic acid. Proc Natl Acad Sci USA. 2000;97: 841-846.

25. Vissers MC, Bozonet SM, Pearson JF, Braithwaite LJ. Dietary ascorbate intake affects steady state tissue concentrations in vitamin C-deficient mice: tissue deficiency after suboptimal intake and superior bioavailability from a food source (kiwifruit). Am J Clin Nutr. 2011;93: 292-301.

26. Huang Y, Zhu X, Wang L, Liu X, Lu L, Gu W, et al. Genome wide analysis of sex difference in gene expression profiles of bone formations using sfx mice and BXD RI strains. Sci World J. 2014;2014: 584910.

27. Kim W, Bae S, Kim H, Kim Y, Choi J, Lim SY, et al. Ascorbic acid insufficiency induces the severe defect on bone formation via the down-regulation of osteocalcin production. Anat Cell Biol. 2013;46: 254-261.

28. Aghajanian P, Hall S, Wongworawat MD, Mohan S. The roles and mechanisms of actions of vitamin $\mathrm{C}$ in bone: new developments. J Bone Miner Res. 2015;30: 1945-1955.

29. Franceschi RT, Iyer BS. Relationship between collagen synthesis and expression of the osteoblast phenotype in MC3T3-E1 cells. J Bone Miner Res. 1992;7: 235-246.

30. Kim J, Xing W, Wergedal J, Chan JY, Mohan S. Targeted disruption of nuclear factor erythroid-derived 2-like 1 in osteoblasts reduces bone size and bone formation in mice. Physiol Genomics. 2010;40: 100-110.

31. Cheng S, Xing W, Pourteymoor S, Mohan S. Conditional disruption of the prolyl hydroxylase domain-containing protein 2 (Phd2) gene defines its key role in skeletal development. J Bone Miner Res. 2014;29: 2276-2286.

32. Hadzir SN, Ibrahim SN, Abdul Wahab RM, Zainol Abidin IZ, Senafi S, Ariffin ZZ, et al. Ascorbic acid induces osteoblast differentiation of human suspension mononuclear cells. Cytotherapy. 2014;16: 674-682.

33. Murad S, Grove D, Lindberg KA, Reynolds G, Sivarajah A, Pinnell SR. Regulation of collagen synthesis by ascorbic acid. Proc Natl Acad Sci USA. 1981;78: 2879-2882.

34. Melhus H, Michaëlsson K, Holmberg L, Wolk A, Ljunghall S. Smoking, antioxidant vitamins, and the risk of hip fracture. J Bone Miner Res. 1999;14: 129-135.

35. Hall SL, Greendale GA. The relation of dietary vitamin C intake to bone mineral density: results from the PEPI study. Calcif Tissue Int. 1998;63: 183-189.

36. Léone J, Delhinger V, Maes D, Scheer C, Pennaforte JL, Eschard JP, et al. Rheumatic manifestations of scurvy. A report of two cases. Rev Rhum Engl Ed. 1997;64: 428-431.

37. Londono J, Valencia P, Santos AM, Gutiérrez LF, Baquero R, Valle-Oñate R. Risk factors and prevalence of osteoporosis in premenopausal women from poor economic backgrounds in Colombia. Int J Womens Health. 2013;5: 425-430.

38. Inada M, Matsumoto C, Miyaura C. Animal models for bone and joint disease. Ovariectomized and orchidectomized animals. Clin Calcium. 2011;21: 164-170.

39. Campbell EJ, Dachs GU. Current limitations of murine models in oncology for ascorbate research. Front Oncol. 2014;4: 282-288.

40. Mayland CR, Bennett MI, Allan K. Vitamin C deficiency in cancer patients. Palliat Med. 2005;19: 17-20.

41. Harris HR, Orsini N, Wolk A. Vitamin C and survival among women with breast cancer: a meta-analysis. Eur J Cancer. 2014;50: 1223-1231.

42. Bai XY, Qu X, Jiang X, Xu Z, Yang Y, Su Q, Wang M, $\mathrm{Wu} \mathrm{H}$. Association between dietary vitamin $\mathrm{C}$ intake and risk of prostate cancer: A meta-analysis involving 103,658 subjects. J Cancer. 2015;6: 913-921.

43. Wang G, Yin T, Wang Y. In vitro and in vivo assessment of high-dose vitamin $\mathrm{C}$ against murine tumors. Exp Ther Med. 2016;12: 3058-3062.

44. Cha J, Roomi MW, Ivanov V, Kalinovsky T, Niedzwiecki A, Rath M. Ascorbate supplementation inhibits growth and metastasis of B16FO melanoma and 4T1 breast cancer cells in vitamin C-deficient mice. Int J Oncol. 2013;42: 55-64.

45. Goh WW, Lee YH, Ramdzan ZM, Sergot MJ, Chung M, Wong L. Proteomics signature profiling (PSP): a novel contextualization approach for cancer proteomics. J Proteome Res. 2012;11: 1571-1581. 
46. Ittner LM, Götz J. Pronuclear injection for the production of transgenic mice. Nat Protoc. 2007;2: 1206-1215.

47. Lai CW, Chen HL, Tsai TC, Chu TW, Yang SH, Chong $\mathrm{KY}$, et al. Sexually dimorphic expression of eGFP transgene in the Akr1A1 locus of mouse liver regulated by sex hormone-related epigenetic remodeling. Sci Rep. 2016;6: 24023

48. Lai CW, Chen HL, Yen CC, Wang JL, Yang SH, Chen CM. Using dual fluorescence reporting genes to establish an in vivo imaging model of orthotopic lung adenocarcinoma in mice. Mol Imaging Biol. 2016;18: 849-859.

49. Kuo CW, Shen CJ, Tung YT, Chen HL, Chen YH, Chang $\mathrm{WH}$, et al. Extracellular superoxide dismutase ameliorates streptozotocin-induced rat diabetic nephropathy via inhibiting the ROS/ERK1/2 signaling. Life Sci. 2015;135: 77-86.

50. Tung YT, Huang PW, Chou YC, Lai CW, Wang HP, Ho $\mathrm{HC}$, et al. Lung tumorigenesis induced by human vascular endothelial growth factor (hVEGF)-A165 overexpression in transgenic mice and amelioration of tumor formation by miR-16. Oncotarget. 2015;6: 10222-10238. doi: 10.18632/ oncotarget.3390.

51. Tu MY, Chen HL, Tung YT, Kao CC, Hu FC, Chen CM. Short-term effects of kefir-fermented milk consumption on bone mineral density and bone metabolism in a randomized clinical trial of osteoporotic patients. PLoS One. 2015;10: e0144231.
52. Chen HL, Tung YT, Chuang CH, Tu MY, Tsai TC, Chang $\mathrm{SY}$, et al. Kefir improves bone mass and microarchitecture in an ovariectomized rat model ofpostmenopausal osteoporosis. Osteoporos Int. 2015;26: 589-599.

53. Chang YT, Chen CM, Tu MY, Chen HL, Chang SY, Tsai $\mathrm{TC}$, et al. Effects of osteoporosis and nutrition supplements on structures and nanomechanical properties of bone tissue. J Mech Behav Biomed Mater. 2011;4: 1412-1420.

54. Bouxsein ML, Boyd SK, Christiansen BA, Guldberg RE, Jepsen KJ, Müller R. Guidelines for assessment of bone microstructure in rodents using micro-computed tomography. J Bone Miner Res. 2010;25: 1468-1486.

55. Gaddy-Kurten D, Coker JK, Abe E, Jilka RL, Manolagas SC. Inhibin suppresses and activin stimulates osteoblastogenesis and osteoclastogenesis in murine bone marrow cultures. Endocrinology. 2002;143: 74-83.

56. Mun SH, Won HY, Hernandez P, Aguila HL, Lee SK. Deletion of CD74, a putative MIF receptor, in mice enhances osteoclastogenesis and decreases bone mass. J Bone Miner Res. 2013;28: 948-959. 